Article

\title{
Catalytic Fast Pyrolysis of Poly (Ethylene Terephthalate) (PET) with Zeolite and Nickel Chloride
}

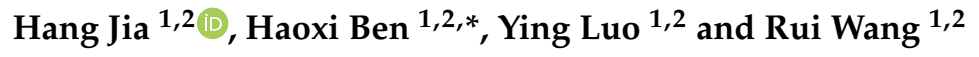 \\ 1 Key Laboratory of Energy Thermal Conversion and Control of Ministry of Education, Southeast University, \\ Nanjing 210096, China; 18707126420@163.com (H.J.); danteli_an2410@163.com (Y.L.); \\ wr3502140301@163.com (R.W.) \\ 2 School of Energy and Environment, Southeast University, Nanjing 210096, China \\ * Correspondence: benhaoxi@seu.edu.cn; Tel.: +86-188-5107-5775
}

Received: 3 January 2020; Accepted: 10 March 2020; Published: 23 March 2020

\begin{abstract}
The pyrolysis of poly (ethylene terephthalate) (PET) in the presence of ZSM-5 zeolite and $\mathrm{NiCl}_{2}$ as a catalyst was studied at different temperatures under $\mathrm{N}_{2}$ atmosphere. Quantitative ${ }^{13} \mathrm{C}$ nuclear magnetic resonance (NMR) and Fourier transform infrared spectroscopy (FT-IR) were applied to characterize the waxy and solid residue. The carboxyl and aliphatic hydroxyl groups in the waxy residue have been greatly depleted after the use of zeolite during pyrolysis on the basis of the results of ${ }^{13} \mathrm{C}$ NMR and FT-IR analysis. The proportion of aromatic hydroxyl groups increased by $21.82 \%$ when the mass ratio of zeolite to PET was set to 2.0/1.0. The results indicate that ZSM-5 is able to facilitate the decomposition of carboxyl, aliphatic groups, and ether bonds in the primary products produced from the pyrolysis of PET. In addition, the deoxygenation effects on the waxy products have been significantly enhanced with the addition of zeolite based on the results of NMR.
\end{abstract}

Keywords: poly (ethylene terephthalate) (PET); pyrolysis; zeolite; $\mathrm{NiCl}_{2}$; Fourier transform infrared spectroscopy (FT-IR); ${ }^{13} \mathrm{C}$ nuclear magnetic resonance (NMR); pyrolysis mechanism

\section{Introduction}

Polyethylene terephthalate (PET) is one of the most widely used polymers in packaging, electronics, storage, and personal care products across the world. Then, the extensive use of PET led to the growth of PET waste accumulation. For example, according to data from the European Union, in 2018, 29.1 million tons of plastic waste including PET were generated; only approximately $32.5 \%$ was recycled and $42.6 \%$ was recovered through energy recovery techniques. Regrettably, $27.3 \%$ went to landfills [1]. However, plastics take up to hundreds of years to be biodegraded naturally, and they currently occupy a large volume of costly landfill space, which causes serious environmental problems. However, plastics waste recycling has increased almost $80 \%$ in the last 10 years [1], which is similar to the packaging recycling (74\%). Since PET accounts for a large proportion of the packaging materials, it is vital to explore more reliable and sustainable methods to recycle PET waste.

Thermochemical conversion is a promising route to produce clean energy and chemical raw materials from these waste plastics while diverting them from landfills [2,3]. It is an efficient way to degrade polymerized molecules into less complex ones by heating in a space filled with inert gas. The pyrolysis of PET is regarded as the most desirable method to convert PET waste into fuels and useful chemical products [4-6]. Among them, pyrolysis oils are the primary products; however, these have several challenging properties including a mixture of compounds with a high oxygen content, poor volatility, and high acidity and viscosity due to the presence of benzoic acid and terephthalic acid and so on [7-10], which significantly limits its usage as fuels or chemicals. Hence, catalytic pyrolysis 
seems to be a feasible and indispensable method to solve this problem due to its decarboxylation or decarbonylation ability for pyrolytic vapor.

Many researchers have examined the influence of kinds of catalysts such as zeolite and metal salts to increase the field of pyrolysis oils and upgrade the properties of liquid products during the pyrolysis of PET. For instance, Kumagai et al. used a vertical tube reactor to pyrolyze different kinds of plastics including PET at 600 and $700{ }^{\circ} \mathrm{C}$ in the presence and absence of either $\mathrm{CaO}$ and or $\mathrm{Ca}(\mathrm{OH})_{2}$. They concluded that the production of sublimating substances during the pyrolysis of PET was significantly reduced after the addition of $\mathrm{CaO}$ [11]. Furthermore, Masuda et al. developed a new method to decompose terephthalic acid produced from the pyrolysis of PET into useful liquid hydrocarbons, using inexpensive catalysts such as transition metal oxides, including $\mathrm{FeOOH}$, $\mathrm{Fe}_{2} \mathrm{O}_{3}, \mathrm{Ni}(\mathrm{OH})_{2}$, and $\mathrm{NiO}$. They compared the effects of the above catalysts on the decomposition of terephthalic acid and found that $\mathrm{FeOOH}$ showed high activity, yielding no sublimate substances among the metal oxides [12]. Du et al. investigated ZSM-5 zeolite, $\mathrm{CaO}$ as catalysts in the pyrolysis of PET-based waste carpet at different temperatures and using different pyrolysis methods and analyzed the gas and liquid products by gas chromatography mass spectrometry (GC-MS). They studied different heating rates, thermal, and catalytic pyrolysis, with/without the co-feeding of steam and indicated that the conversion from PET to aromatic hydrocarbons was favored at higher temperatures and that slow heating rates can facilitate the production of benzene. They also found that ZSM- 5 zeolite and $\mathrm{CaO}$ are both effective catalysts to completely deoxygenate the pyrolytic products [13]. A tandem micro-pyrolyzer was used to study the pyrolytic vapor produced from the pyrolysis of different types of plastics including polyethylene (PE), polypropylene (PP), polystyrene (PS), and PET using H-ZSM-5 as catalyst from 300 to $800^{\circ} \mathrm{C}$ by Xue et al. [14]. They found that the decomposition of PET was reduced, but the formation of aromatic hydrocarbons was promoted compared to the results of pyrolysis without catalyst. Catalytically co-pyrolyzing PE and PET was also investigated and indicated that the yield of aromatic was increased but the yield of solid residue was reduced. Miandad et al. used modified natural zeolite (NZ), thermal activation zeolite (TA-NZ), and acid activation zeolite as catalysts in the pyrolysis of PET and other plastics at $600{ }^{\circ} \mathrm{C}$ and found that the optimal yield of pyrolysis oil (approximately $30 \%$ ) was reached when the zeolite was activated by $\mathrm{HNO}_{3}$. Similar to the previous results, the analysis of pyrolysis oil was carried out by GC-MS and Fourier transform infrared spectroscopy (FT-IR) and indicated that the main components in the oil were aromatic compounds [15]. Al-asadi et al. pyrolyzed real PET-containing waste plastics in a horizontal tubular reactor with different Ni-loaded catalysts, including Ni/ZSM5, Ni/y-zeolite, Ni/beta-zeolite, and Ni/natural zeolite from 600 to $900{ }^{\circ} \mathrm{C}$. They concluded that the highest yield of oil product was achieved in the presence of $\mathrm{Ni} / \gamma$-zeolite and $\mathrm{Ni} / \beta$-zeolite and oxygenates were significantly converted to non-oxygenated compounds in the oil products using Ni/ZSM-5 [16]. On the other hand, Laura $S$ et al. chose sulfated zirconia (SZ) as catalyst in the pyrolysis of PET to recover benzoic acid products. They found that the recovery of benzoic acid achieved $26 \mathrm{wt} \%$ in the wax when the ratio of catalyst to PET increased up to $10 \mathrm{wt} \%$ [17].

In addition, compared to the massive research studies of other polymers such as PS, PE, and PP [18-22], the current research on PET is mainly focused on the pyrolysis of its mixture with other type of plastics or biomass. Sembiring et al. carried out the pyrolysis of the mixture of PP and PET with using a mixture of natural zeolite and bentonite as catalyst from 400 to $500{ }^{\circ} \mathrm{C}$. They found that the proportion of each pyrolysis product was significantly influenced by temperature and catalyst, and the catalyst facilitated the further decomposition of solid products to produce more liquid oils. The addition of catalyst caused a dramatically increase of non-oxygenated aromatic hydrocarbons. Furthermore, consistent with the pyrolysis of PET, the main problem of the recovery of products from the pyrolysis of lignin was its high oxygen content and poor volatility. Hence, the idea of pyrolyzing lignin may be referenced [23]. Geng et al. used analytical pyrolysis methods (Py-GC-MS) to analyze the pyrolytic vapor obtained from the pyrolysis of alkali lignin with nickel formate. They concluded that the liquid yield was greatly improved using nickel formate as the additive and the contents of 
alkylphenols and aromatics in the pyrolysis oil were significantly promoted as well [24]. French et al. attempted to upgrade the pyrolysis vapors produced from lignin using zeolite as additives. They found that the optimal yield of hydrocarbons (approximately $16 \mathrm{wt} \%$, including $3.5 \mathrm{wt} \%$ of toluene) was reached with the use of nickel, cobalt, iron, and gallium-substituted ZSM-5 zeolite [25]. Furthermore, it was reported that the selectivity of aromatic hydrocarbon can be influenced by the introduction of $\mathrm{Ni}^{2+}[26]$.

Driven by prior studies in PET or lignin pyrolysis, we found that most of the previous catalytic pyrolysis studies have focused on the effect of several parameters such as temperature, heating rate, different type of PET, and common catalysts on pyrolysis products and its distribution. Nevertheless, only a few studies investigated the synergistic effect of ZSM-5 zeolite, nickel chloride, and their dosage and temperature on the pyrolysis of PET. In view of the effective application of nickel salts and nickel-substituted zeolite in the pyrolysis of lignin coupled with the inexpensive price of nickel chloride, the work presented here focuses on the relationship between the structure of liquid products and the dosage of catalyst and temperature. Furthermore, different temperature and catalyst dosages have been studied to figure out the mechanism of PET pyrolysis. Based on the detailed structure information of pyrolytic products provided by ${ }^{13} \mathrm{C}$ nuclear magnetic resonance (NMR) analysis, the change of functional groups in the liquid products can be easily found before and after using the catalyst [27].

\section{Materials and Methods}

\subsection{Materials}

PET pellets with three different molecular weights $(\mathrm{Mw}=50,000 \mathrm{~g} / \mathrm{mol})$ were all purchased from HuaChuang Plastic Co., Guangdong, China. The purity of PET power exceeds 99\%. The PET pellets (particle size: $3 \mathrm{~mm}$ ) were grinded and sieved to gain the PET powder with the size of 100-150 $\mu \mathrm{m}$. The characterization of PET plastics is shown in Table 1. Overall, the results of characterization are similar to that in the most recent literature $[8,10,13]$. PET had a high carbon content and relatively low hydrogen content due to the existence of aromatic rings, ester, and a carboxylic group as described in Figure 1. The C, H, and O composition of the sample was $61.87 \mathrm{wt} \%, 4.35 \mathrm{wt} \%$, and $33.78 \mathrm{wt} \%$, respectively, which is similar to the theoretical values for pure PET (C, $62.5 \mathrm{wt} \%$; $\mathrm{H}, 4.2 \mathrm{wt} \%$; $\mathrm{O}, 33.3 \mathrm{wt} \%)$. Proximate analysis was also carried out under reported condition [11] and was listed in Table 1. The contents of volatiles, fixed carbon, and ash of PET were $88.54 \%$, 9.37\%, and $2.09 \%$, respectively, suggesting the formation of large amounts of oil or gas products during pyrolysis.

Table 1. Proximate and ultimate analysis of poly (ethylene terephthalate) (PET).

\begin{tabular}{cccc}
\hline $\begin{array}{c}\text { Proximate Analysis } \\
\text { (wt \% dry basis) }\end{array}$ & Volatiles & Fixed Carbon $^{\text {a }}$ & Ash \\
\cline { 2 - 4 } & 88.54 & 9.37 & 2.09 \\
\hline $\begin{array}{c}\text { Ultimate Analysis } \\
\text { (wt \% dry basis) }\end{array}$ & $\mathrm{C}$ & $\mathrm{H}$ & $\mathrm{O}^{\mathrm{a}}$ \\
\cline { 2 - 4 } & 61.87 & 4.35 & 33.78 \\
\hline
\end{tabular}

\subsection{Catalyst Preparation}

ZSM-5 zeolite (NKF-5, $\mathrm{SiO}_{2} / \mathrm{Al}_{2} \mathrm{O}_{3}=46: 1$ ) was purchased from Nankai University Catalyst Co., Ltd., Tianjin, China. The zeolite was calcined at $550{ }^{\circ} \mathrm{C}$ for $6 \mathrm{~h}$ in the quartz tube under inert atmosphere in order to avoid water absorption of the hyperthermal zeolite during the cooling process before the experiment. The zeolite was immediately filled into a dry bottle for subsequent experiments when the inside temperature of quartz tube is near the room temperature.

$\mathrm{NiCl}_{2}$ catalyst was prepared by using nickel chloride hexahydrate as a precursor. The hydrate was ground to powders and then put into the dryer. The powders were dried to remove its own crystal water at $140^{\circ} \mathrm{C}$ for $2 \mathrm{~h}$. Meanwhile, the powders needed to be stirred manually to avoid clumping. 
The sign of complete removal of crystal water is that the color of powders changes from dark green to khaki yellow.

\subsection{Tube Furnace Pyrolysis}

The thermal and catalytic fast pyrolysis experiments of PET were carried out under $\mathrm{N}_{2}$ atmosphere in a horizontal tubular reactor $(60 \mathrm{~mm}$ (ID) $\times 1000 \mathrm{~mm}(\mathrm{~L}))$, and its schematic diagram is displayed in Figure 1. The quartz boat filled with PET sample and catalyst was first placed inside the quartz tube embedded in the tube groove inside the electric furnace. Then, the quartz tube was connected to the $\mathrm{N}_{2}$ cylinder through the gas pipe and continuously flushed with nitrogen at a flow rate of $200 \mathrm{~mL} / \mathrm{min}$ for $10 \mathrm{~min}$ to eliminate any oxygen in the tube. The temperature inside the quartz tube reactor was measured by a K-type thermocouple connected to a temperature recorder, and the real-time of temperature and heating in the reactor during the operation can therefore be reflected effectively. The tube reactor loaded with the PET sample and catalyst was inserted into the preheated furnace immediately as soon as the temperature reached the predetermined value. After finishing the above operations, the quartz boat loaded with PET was heated up to a diverse final temperature $\left(450,600^{\circ} \mathrm{C}\right)$, which needed to be held for $30 \mathrm{~min}$ to ensure that the pyrolysis is fully completed. The solid residue and the gas residence time was adjusted to 30 and 5 min respectively at an extremely fast heating rate. It can also contribute to the full decomposition of the volatiles released.

As is shown in Figure 1, the condenser was connected downstream of the quartz tube, which was linked with a freezing fluid circulation device, which used ethanol as frozen liquid inside, and the condensation temperature was set to $-5{ }^{\circ} \mathrm{C}$. The other outlet of the condenser is followed by a round-bottom flask immersed in an ice-salt bath (approximately $0-3^{\circ} \mathrm{C}$ ). The volatiles generated by the pyrolysis of PET were condensed in the condenser and flowed into the flask to be collected. Meanwhile, the incondensable gas was collected into the gas-sampling bag after passing through the dryer, and then the gas was discharged into the air after the treatment. Finally, the remaining products deposited in the quartz boat were collected and weighed to determine the yield as soon as the heating area cooled down to room temperature.

Two different pyrolysis products were collected at the end of every experiment: the pyrolysis char that remained in the quartz boat, the condensable waxy products collected inside the tube, and the connections between the tube and the condenser. The recovered waxy products mixed with pyrolysis oil and a small amount of solid powder accounting for only a fraction of all solid powder can only be dissolved in pyridine. Dhahak et al. tried to use other solvents such as water, ethanol, hot methanol, acetone and acetate, etc. to dissolve the waxy product and found that no other solvents work better than pyridine [28]. Therefore, the waxy product that adhered to the wall of the quartz tube needs to be washed with pyridine and followed by the evaporation of mixed liquid after each experiment. The majority of solid powder can be collected in the condenser and analyzed in the further study.

For each experiment, the quartz boat, the condenser, the connections, and other containers were all weighed before and after the pyrolysis. After that, the solid residue can be collected in the sample holder after the temperature drops to room temperature under $\mathrm{N}_{2}$ atmosphere, and the waxy products can also be collected through the above series of operation. The yield of solid residue and waxy products (including the waxy products that adhered to the wall of the quartz tube and connections and the rest of the solid powder produced during the pyrolysis of PET) were calculated by dividing the mass of the products by the initial mass of the sample. Meanwhile, the yield of the pyrolysis gas was calculated by difference. The repeatability of the experiments was confirmed by performing each thermal and catalytic fast pyrolysis experiment at least three times. The experimental standard deviation is reported in the experimental results in the form of error bars.

\subsection{Analysis of Pyrolysis Products by FT-IR}

The recovered solid power was made into samples by compression using $\mathrm{KBr}$ as the background and then was characterized by a Nicolet iS 10 Fourier transform infrared spectroscopy (FT-IR) 
spectroscopy purchased from Thermo Scientific Inc., Waltham, MA, USA. The spectra of FT-IR were obtained in the range of 3800 to $500 \mathrm{~cm}^{-1}$. The samples were analyzed repeatedly to acquire the most suitable one.

\subsection{Analysis of the Waxy by ${ }^{13} \mathrm{C} N M R$}

The waxy products produced from the pyrolysis of PET under different catalytic conditions were characterized by an AVANCE III HD $600 \mathrm{MHz}$ Spectrometer purchased from Bryker Inc., Zurich, Switerland. The sample, which weighed $500 \mathrm{mg}$, was dissolved in $600 \mu \mathrm{L}$ of deuterated dimethyl sulfoxide (DMSO-d6). The solvent peak appears as sevenfold peaks in ${ }^{13} \mathrm{C}$ NMR spectra and the position of the peaks was at $39.52 \mathrm{ppm}$. In addition, the number of scans was 1024 and the pulse delay was set as $5 \mathrm{~s}[29,30]$. The ${ }^{13} \mathrm{C}$ NMR spectra were all processed in MestReNova v12.0 ((Mestrelab Research, Santiago De Compostela, Spain).

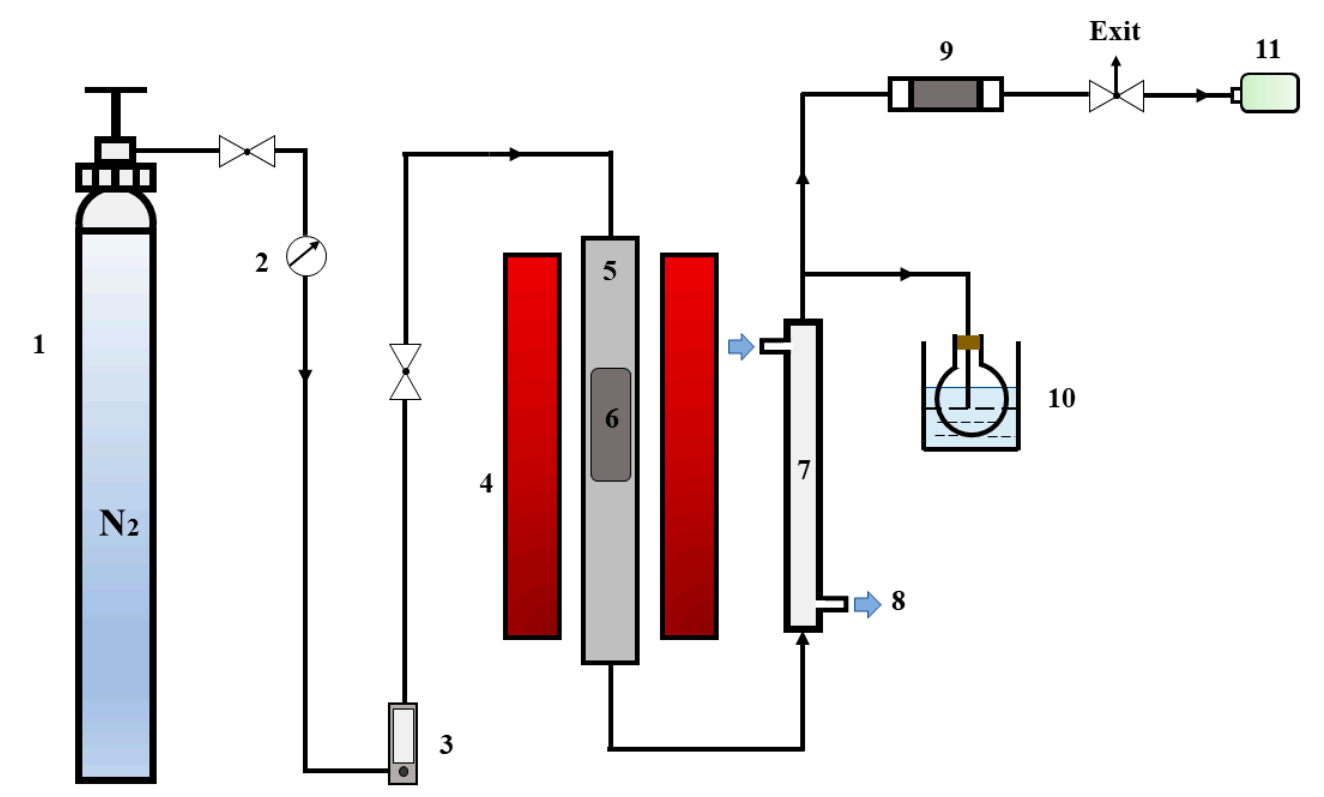

Figure 1. Schematic diagram of experimental apparatus. 1. $\mathrm{N}_{2}$ cylinder; 2. Pressure gauge; 3 . Flow meter; 4. Tube furnace; 5 . Quartz tube; 6. Quartz boat; 7. Condenser; 8. Cooling ethanol; 9. Quicklime dryer; 10. Ice-water trap; 11. Sampling bag.

\section{Results}

The structure of PET is described in Figure 2. According to the studies of Artetxe and Du, the random scission of the ester bonds leads to the formation of carboxyl groups and vinyl ester, etc. $[8,13]$ when it is exposed to high temperatures $\left(\geq 385^{\circ} \mathrm{C}\right)[28]$. Then, some smaller molecular bonds including acetaldehyde, $\mathrm{CO}_{2}, \mathrm{CO}$, and ethylene were formed subsequently due to the instability of vinyl ester [31,32].

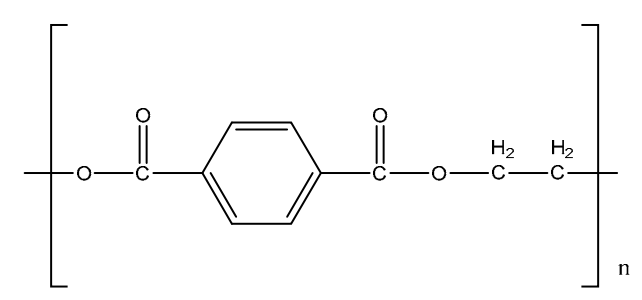

Figure 2. The structure of poly (ethylene terephthalate) (PET). 


\subsection{Effect of Temperature and Catalyst on the Products' Distribution}

Figure 3 shows the effect of the catalyst to samples mass ratio and the temperature on the overall yield of residue products, the waxy products, and the gas products. The tested operating conditions were set as follows: pyrolysis temperature from 450 to $600{ }^{\circ} \mathrm{C}$, the residence time of pyrolytic vapors in the quartz tube (approximately $20 \mathrm{~s}$ ) and different catalyst dosages from 0.5/1.0 to 6.0/1.0. As a result, the catalyst dosage had the biggest impact on the yield of products, followed by the pyrolysis temperature. The addition of a catalyst greatly changed the composition of the pyrolysis products. This is consistent with the results suggested in many previous studies. Generally, the effect of different catalyst formulation on pyrolysis products distribution was not the same. The ZSM- 5 zeolite enhanced the production of the gas while reducing the production of the waxy products. In Figure 3, the yield of waxy products without any catalyst decreased from about $59.50 \mathrm{wt} \%$ and $67.70 \mathrm{wt} \%$ to below $10 \mathrm{wt} \%$ and about $23 \mathrm{wt} \%$ at different pyrolytic temperatures when the ZSM- 5 was added as catalyst. This observation agreed well with the work by Du et al. [13], who carried out the catalytic fast pyrolysis of PET with a mass ratio of 20 at $600{ }^{\circ} \mathrm{C}$ and suggested that a sharp decrease (about 50.8\%) of liquid products was found from $25 \mathrm{C} \%$ to $12.3 \mathrm{C} \%$ with the use of ZSM- 5 as catalyst. On the contrary, the yield of gases increased from about $20 \mathrm{wt} \%$ to over $50 \mathrm{wt} \%$ on average, and it happened in almost all catalyst formulation. Laura et al. [17] used SZ as the catalyst during the pyrolysis of PET and found that the gas yield increased by $29 \%$ (from $38.19 \mathrm{wt} \%$ to $55.91 \mathrm{wt} \%$ ) at $600{ }^{\circ} \mathrm{C}$ with the catalyst/PET mass ratio from $0 \mathrm{wt} \%$ to $10 \mathrm{wt} \%$. This can be explained by the cracking of the $\mathrm{C}-\mathrm{C}$ bond, leading to the formation of gas after using the catalyst [16]. The detailed products yield such as solid residue and waxy products are summarized in Figure $4 \mathrm{a}, \mathrm{b}$. Increasing the catalyst proportion did not have a clear effect on the yield of pyrolysis char, but it decreased the yield of the waxy product at $450^{\circ} \mathrm{C}$. As a result, the yield of the gases drastically increased. The yield of pyrolysis char was similar to the control group after the use of different dosages of zeolite, which indicated that the primary decomposition of PET was barely influenced by the zeolite. However, the situation based on the results of different nickel-supported zeolite catalyst such as $\mathrm{Ni} / \mathrm{ZSM}-5, \mathrm{Ni} / \mathrm{y}$-zeolite, etc. varies widely. Al-asadi et al. [16]. indicated that $\mathrm{Ni} / \mathrm{ZSM}-5$ and Ni/y-zeolite had the same influence on the formation of solid residue (decreased from $46 \mathrm{wt} \%$ to around $15 \mathrm{wt} \%$ ), which agreed well with the results of our work, whereas a relatively high yield of solid residue was achieved using $\mathrm{Ni} / \mathrm{b}$-zeolite and $\mathrm{Ni} /$ natural zeolite. In addition, this finding does not apply to the conditions using nickel chloride as a catalyst. The yield of solid residue is much lower when applying nickel chloride as a catalyst compared to ZSM-5, whereas increasing the ratio of catalyst will also lead to a further decline in solid residue yield, which was consistent with a previous study by Geng et al. [24] who observed a significant decrease of solid residue (approximately 21\%) and an obvious increase of liquid products (approximately 20\%) during the pyrolysis of alkali using nickel formate. The addition of ZSM-5 zeolite led to the decrease of the waxy product during the pyrolysis. On the contrary, the yield of gas increased after the use of those two types of catalysts. When the temperature increased to $600{ }^{\circ} \mathrm{C}$, the solid residue yield maximized when the waxy yield slumped at a catalyst/plastic mass ratio of 2 . After this, the solid residue yield decreased with the catalyst $(14.60 \mathrm{wt} \%$ at a ratio of 4 and $10.50 \mathrm{wt} \%$ at a ratio of 6). Based on the results relating to the yield of pyrolysis products, we can conclude that the secondary decomposition of volatile products was enhanced to produce more gas products at the expense of the waxy products with the use of ZSM- 5 zeolite. 


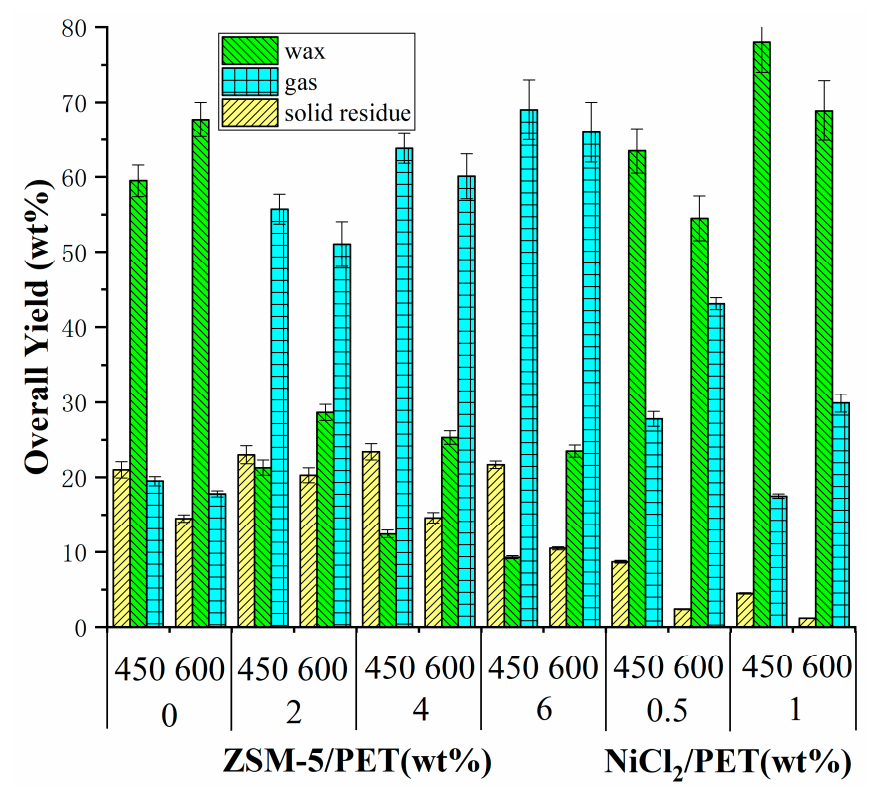

Figure 3. Yields of solid residue, the waxy products, and gas for the pyrolysis of PET with 0.0/1.0-6.0/1.0 ( $\left.\mathrm{W}_{\mathrm{ZSM}-5} / \mathrm{W}_{\mathrm{PET}}\right)$ of ZSM-5 zeolite, 0.5/1.0-1.0/1.0 $\left(\mathrm{W}_{\mathrm{NiCl} 2} / \mathrm{W}_{\mathrm{PET}}\right)$ of $\mathrm{NiCl}_{2}$ as catalyst at different temperatures $\left(450\right.$ and $\left.600{ }^{\circ} \mathrm{C}\right)$.
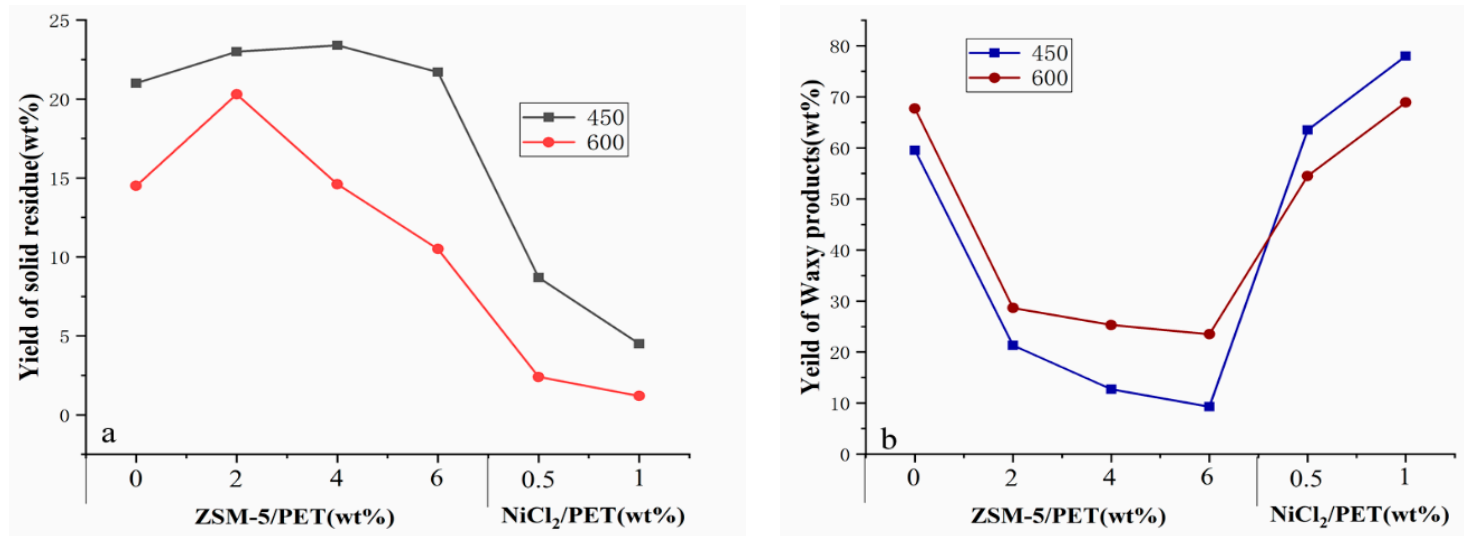

Figure 4. Effect of temperature and catalyst: PET mass ratio on the yield of solid residue (a) and waxy products $(\mathbf{b})$.

Based on the finding revealed in Figure 4a,b, the catalyst proportion was regarded to have a more profound effect on the PET pyrolysis at a higher temperature $\left(600{ }^{\circ} \mathrm{C}\right)$. For instance, increasing the catalyst (ZSM-5) to PET mass ratio at $450{ }^{\circ} \mathrm{C}$ from 0 to 6 resulted in a $3.33 \%$ increase of the solid residue (from $21 \mathrm{wt} \%$ to $21.7 \mathrm{wt} \%$ ) while at $600{ }^{\circ} \mathrm{C}$, the solid residue decreased by $27.58 \%$ (from $14.5 \mathrm{wt} \%$ to $10.5 \mathrm{wt} \%$ ). The same pattern applies for the use of $\mathrm{NiCl}_{2}$ as a catalyst for the pyrolysis of PET. The waxy yield increased by $26.42 \%$ (from $54.5 \mathrm{wt} \%$ to $68.9 \mathrm{wt} \%$ ) at $600{ }^{\circ} \mathrm{C}$, while it rose by $22.83 \%$ (from $63.5 \mathrm{wt} \%$ to $78 \mathrm{wt} \%$ ) at $450{ }^{\circ} \mathrm{C}$. This may indicate that the optimal temperature to activate both of two catalysts to promote the secondary decomposition is more than $450{ }^{\circ} \mathrm{C}$, which is line with the study of Vouvoudi et al. [33].

\subsection{Effect of Catalyst Dosage on the Wax Composition}

The catalyst was covered on the top of the PET power in the quartz boat in our work. The residence time of pyrolytic volatile was basically determined by the catalyst proportion. Therefore, the effect of ZSM-5 and $\mathrm{NiCl}_{2}$ dosage was studied in the range of mass ratio from 0 to 6 and 01 respectively by adjusting the temperature at $600{ }^{\circ} \mathrm{C}$ and the nitrogen flow rate at a value of $200 \mathrm{~mL} / \mathrm{min}$. 


\subsubsection{Analysis of Solid Powder by FT-IR}

Figure 5 shows the FT-IR analysis of the solid powder collected in a pipe at $450{ }^{\circ} \mathrm{C}$ and $600{ }^{\circ} \mathrm{C}$ without a catalyst with the gas flow rate of $200 \mathrm{~mL} / \mathrm{min}$. Based on the infrared spectrum, we can conclude that the temperature had a very limited effect on the functional groups composition of solid powder, which is inconsistent with the study of Laura et al. [17]. Figure 6 shows the spectra of solid products with different catalyst/PET mass ratios at $600{ }^{\circ} \mathrm{C}$ respectively. The spectrum of solid powder was distinguished by the peaks relating to olefin and carbonyl groups. Aromatic $(\mathrm{C}=\mathrm{C})$, $\mathrm{C}-\mathrm{H}$ bands, and $(=\mathrm{C}-\mathrm{H})$ bands are situated at $1609(1509), 3065$, and $880 \mathrm{~cm}^{-1}$, respectively [34,35]. Two small but sharp peaks appear at $2982-2827 \mathrm{~cm}^{-1}$, indicating the presence of the C-H stretch in the alkenes, which is similar to the results of Dhahak et al. [28]. In addition, the strongest peak located at approximately $1685 \mathrm{~cm}^{-1}$ presents the $\mathrm{C}=\mathrm{O}$ stretch and the existence of three strong peaks (at approximately 1260, 1085, and $1020 \mathrm{~cm}^{-1}$ ) referring to the ester bond (C-O) stretch reveals the existence of carboxylic acids.

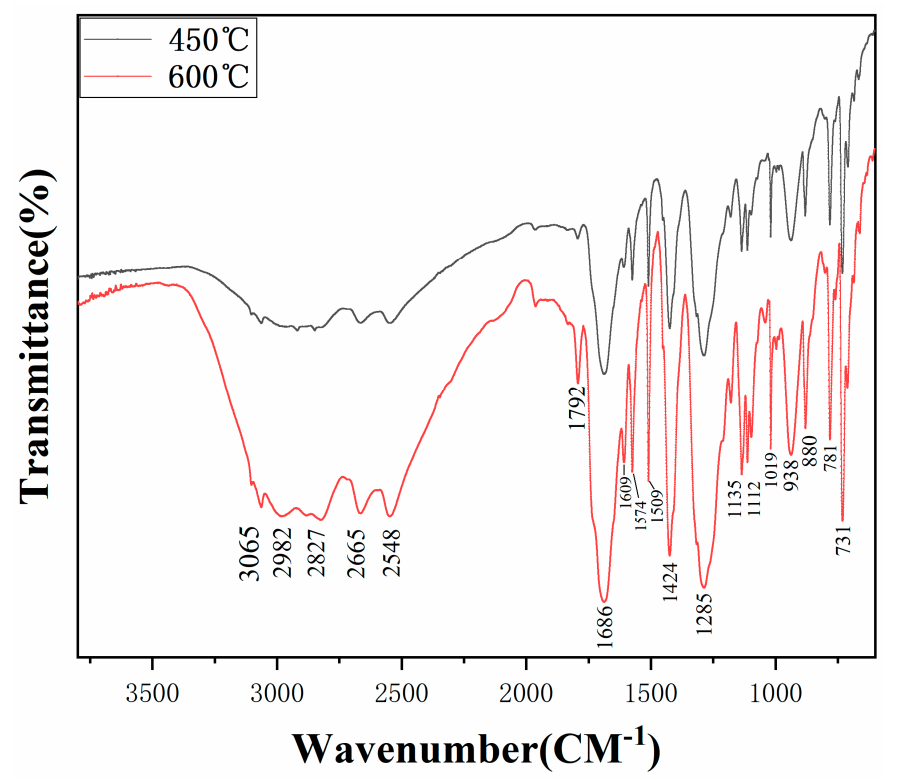

Figure 5. Fourier transform infrared spectroscopy (FT-IR) spectrums of the waxy products obtained at $450{ }^{\circ} \mathrm{C}$ and $600{ }^{\circ} \mathrm{C}$ without catalyst.
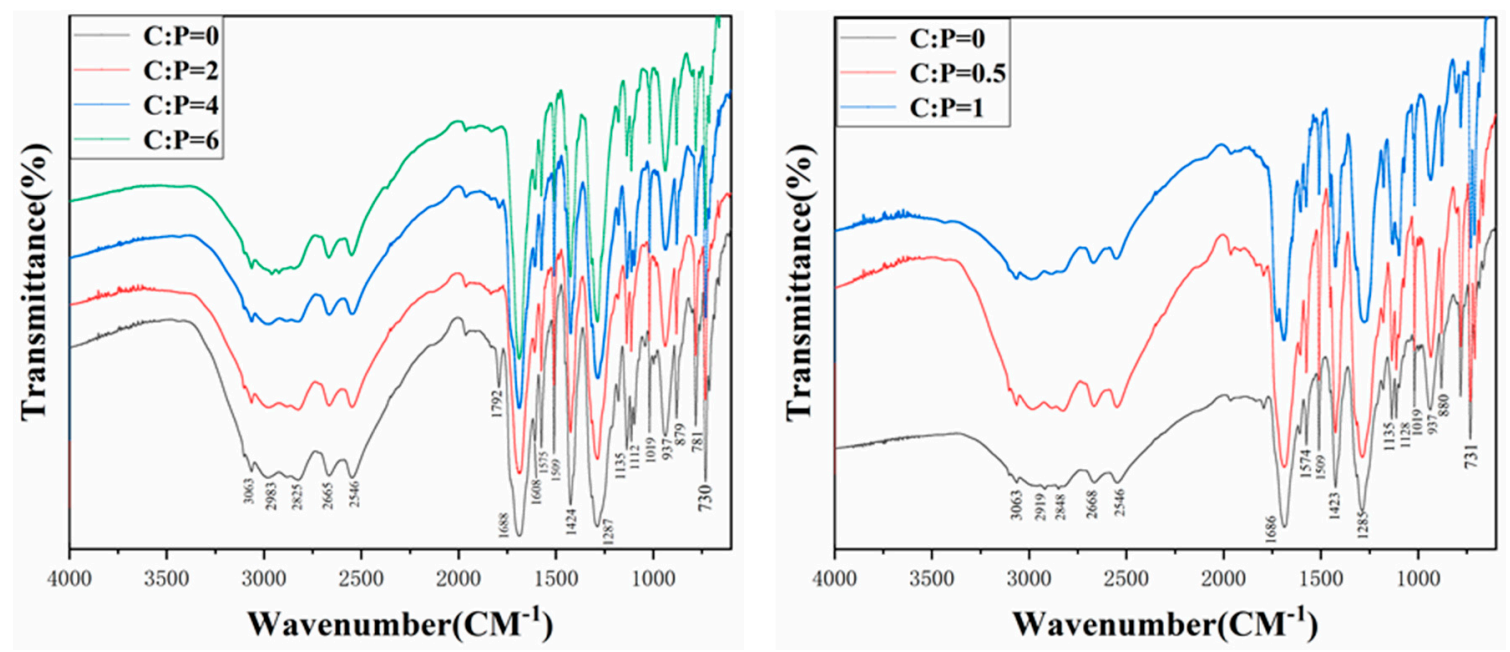

Figure 6. FT-IR spectrums of the wax collected at $600{ }^{\circ} \mathrm{C}$ with different $\left(\mathrm{ZSM}-5\right.$ : left, $\mathrm{NiCl}_{2}$ : right) catalysts. 
These results suggest that the primary solid powders collected in the pipes and condenser are mainly formed by carboxylic acids and esters. The different spectrums at various temperatures and mass ratios of catalyst to plastic were compared with each other, indicating little difference among them. Hence, the results of the spectrum confirmed that PET solid products were mainly composed of aromatic acid. The FT-IR spectrum of solid powder during the pyrolysis of PET shown below did not to some extent agree well with the previous study [32]. A small olefin group $(C=C)$ was found in the spectrum with/without catalyst, while around 60 vol.\%, olefins were confirmed in the tar produced from the pyrolysis without any catalyst [31]. It may be explained by the different sources of solid powder and pyrolysis, which contains solid powder and other liquid products.

\subsubsection{Analysis of Waxy Products by Quantitative ${ }^{13} \mathrm{C}$ NMR}

An elaborate analysis was implemented via ${ }^{13} \mathrm{C}$ NMR to characterize the change of functional groups in the waxy products. A detailed ${ }^{13} \mathrm{C}$ NMR chemical shift assignment range database of components presented in the pyrolysis oil proposed by Ben et al. was applied for the analysis of the waxy products to facilitate this study. The mentioned chemical shift database is summarized in Table 2 .

Table 2. The ${ }^{13} \mathrm{C}$ nuclear magnetic resonance (NMR) chemical shift assignment ranges and functional groups distributions of PET pyrolysis oil based on the chemical shift database created by ben et al. [29].

\begin{tabular}{ccc}
\hline Functional Group & - & Integration Region(ppm) \\
\hline Carbonyl or carboxyl bond & & $215.0-166.5$ \\
Aromatic C-O bond & - & $166.5-142.0$ \\
Aromatic C-C bond & & $142.0-125.0$ \\
Aromatic C-H bond & general & $125.0-95.8$ \\
Aliphatic C-O bond & $95.8-60.8$ \\
Methoxyl-aromatic bond & methyl-aromatic $\left(\mathrm{CH}_{3}-\mathrm{Ar}\right)$ & $60.8-55.2$ \\
& methyl-aromatic at ortho position of a hydroxyl or & $55.2-0.0$ \\
Aliphatic C-C bond & methoxyl group $\left(\mathrm{CH}_{3}-\mathrm{Ar}^{\prime}\right)$ & $21.6-19.1$ \\
& & $16.1-15.4$ \\
\hline
\end{tabular}

The typical ${ }^{13} \mathrm{C}$ NMR spectra for the waxy products produced by the pyrolysis of PET without any catalyst and with ZSM-5 zeolite (2.0/1.0) are shown in Figure 7. As summarized in Figure 8, the integration results of this analysis indicate that the carbonyl groups decreased significantly by $42.02 \%$ and $37.58 \%$ respectively in the wax with catalyst compared to the control. About $50 \%$ of aromatic ether are eliminated after the use of zeolite as a catalyst with the mass ratio of 1.0/2.0. The proportion of aromatic ether substituted carbons (C-O) that existed in the waxy product decreased with the addition of ZSM-5 catalyst, while this result is inconsistent with the analysis of the use of $\mathrm{NiCl}_{2}$. Moreover, the aromatic $\mathrm{C}-\mathrm{C}$ bonds increased the use of the catalyst. This observation agreed well with the results suggested by Du et al. [13], who reported a five-fold and 10-fold increase of benzene and benzene derivatives respectively after the use of ZSM-5. Those results show that the zeolite catalyst could facilitate the cleavage of ether bonds in pyrolysis vapors. Hence, it can be concluded that ZSM-5 zeolite could promote the pyrolysis of the majority of oxygen-containing including carbonyl $(C=O)$, aliphatic $\mathrm{C}-\mathrm{O}$, and aromatic $\mathrm{C}-\mathrm{O}$ in the pyrolytic volatile products, which suggests that a smaller proportion of oxygen-containing groups were discovered in the waxy products remaining after the deoxidation of volatile products produced by the catalytic pyrolysis of PET with ZSM- 5 zeolite as a catalyst. In addition, the proportion of aliphatic $C-C$ bonds decreased by $29.64 \%$ from $21.22 \%$ to $14.93 \%$ in the presence of zeolite. This finding agreed with that of Al-asadi et al. [16], who reported that the concentration of n-olefins and n-paraffins decreased from around $32 \%$ to $23 \%$. On the contrary, the percentage of aromatic $\mathrm{C}-\mathrm{C}$ bonds were found to have an obvious increase after the addition of ZSM-5 zeolite. It seems to confirm that ZSM- 5 enhances all the deoxygenation reactions suggested by $\mathrm{Du}$ et al. [13]. A possible decomposition route of ether bonds in PET is demonstrated as shown in 
Figure 9 [14]. The primary thermal cracking of PET experiences a periodic hydrogen transition process, where the hydrogen connected to $C \beta$ transfers to the oxygen atom located at the $\mathrm{C}=\mathrm{O}$ bond, followed by the consecutive scission of the alkoxy $\mathrm{C} \alpha-\mathrm{O}$ bond and $\mathrm{C} \beta-\mathrm{H}$ bond, which caused the formation of the $\mathrm{C}=\mathrm{C}$ bond and $\mathrm{O}-\mathrm{H}$ bond [10]. Acetaldehyde and ethylene were produced from a McLaffery rearrangement of vinyl benzoate, theoretically [31]. However, aldehyde and vinyl were barely found in the waxy product during the pyrolysis of PET with/without catalyst at any conditions, which is consistent with the results of the previous literature $[13,32,36]$. In addition, the $\mathrm{C}=\mathrm{O}$ bond are also attacked by external protons in BrØnsted acid sites, leading to the formation of benzene free radicals and carbon oxides. Thilakaratne et al. have suggested that benzene free radicals could react with olefins to produce naphthalenes [37]. The analysis of pyrolysis residue and gaseous products in the previous literature proved that the solid residue is mainly composed of polycyclic aromatic hydrocarbons (PAHs) [13], and carbon oxides $\left(\mathrm{CO}_{2}, \mathrm{CO}\right)[12,15]$ account for a large proportion of gases. The same results can be concluded in our work, and it explains the high yield of carbon oxides in catalytic pyrolysis. Therefore, the major pyrolysis products were proved to be terephthalic acid and benzoic acid vinyl ester in the initial stage during the pyrolysis of PET, which agreed well with the studies of Grause et al. [10]. The ester was further transformed into acetophenone owing to the instability of benzoic acid vinyl $[13,38]$. ZSM-5 zeolite has an efficient deoxygenation ability for oxygen-containing groups such as carboxylic and ketone groups [39,40]. Based on the proposed pathways, the results of ${ }^{13} \mathrm{C}$ NMR characterization indicate that the conversion of carbonyl groups to aromatic hydrocarbon was enhanced because of the presence of ZSM- 5 zeolite during the pyrolysis of PET. For the three pyrolytic experiments of PET with different dosages of ZSM-5, the pyrolysis experiments with 2.0/1.0 $\left(\mathrm{W}_{\mathrm{ZSM}-5} / \mathrm{W}_{\mathrm{PET}}\right)$ zeolite was proved to have better upgrading effects than others.

On the other hand, a complete decrease of aliphatic $\mathrm{C}-\mathrm{O}$ was found in the waxy product after the use of nickel chloride as the catalyst. There are more aromatic $\mathrm{C}-\mathrm{C}$ bonds and less aliphatic $\mathrm{C}-\mathrm{C}$ bonds with the increasing catalyst/PET mass ratio. However, the $\mathrm{CH}_{3}-\mathrm{Ar}$ groups are mostly eliminated after pyrolysis with nickel chloride as the catalyst. Nickel chloride promotes the decomposition of alkyl, alkoxy, and branched alkanes on the aromatic ring. This is consistent with the previous study of Zou et al. [5].

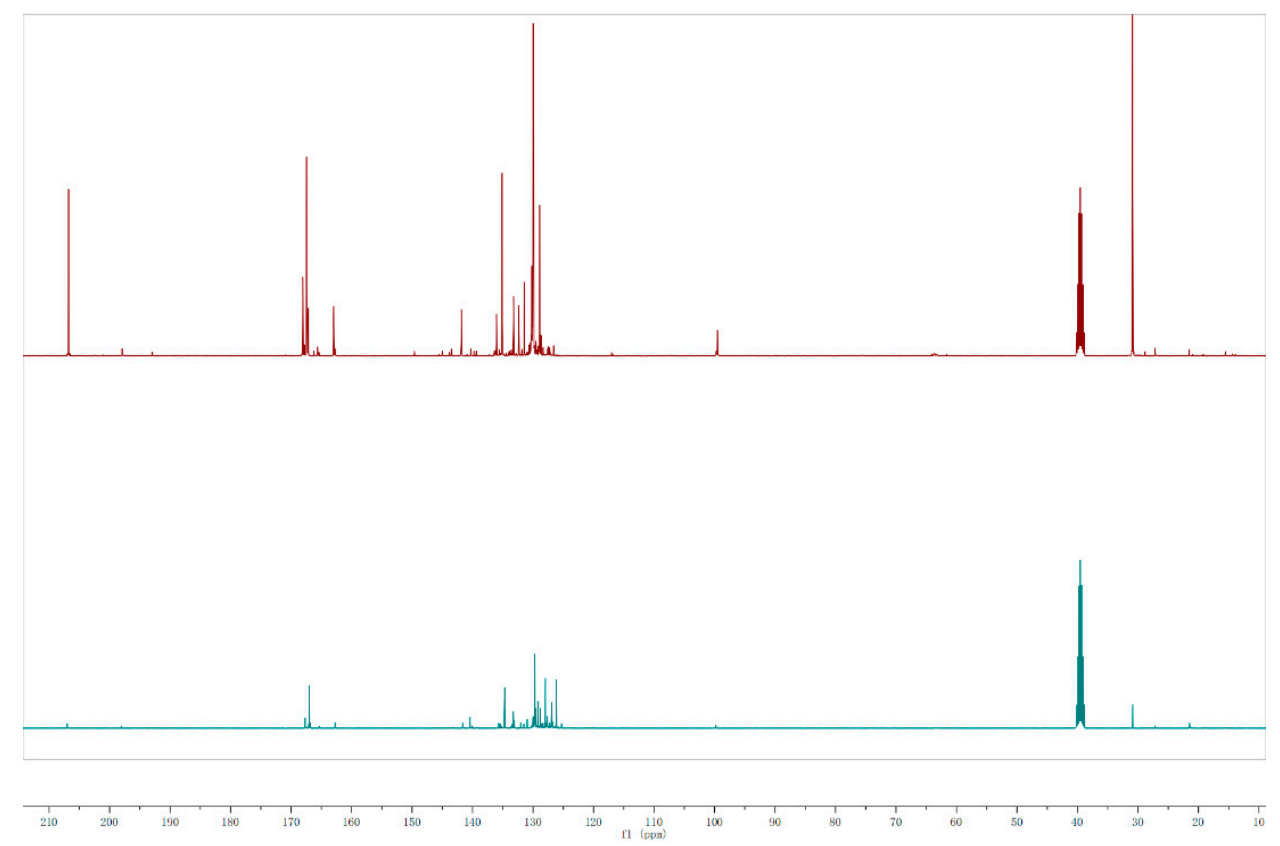

Figure 7. Quantitative ${ }^{13} \mathrm{C}$ NMR spectra for the waxy products produced by the thermal pyrolysis of PET (top) and catalytic fast pyrolysis with ZSM-5(1:2) as a catalyst (bottom) at $600{ }^{\circ} \mathrm{C}$ for $30 \mathrm{~min}$. 


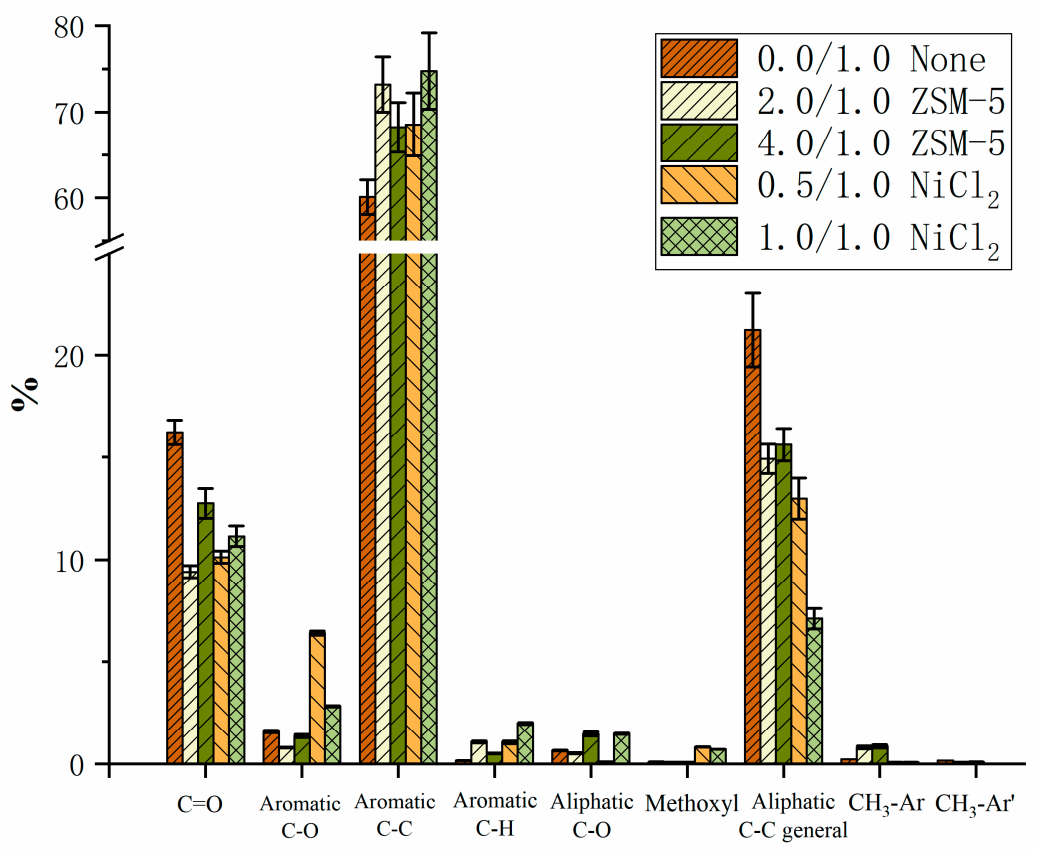

Figure 8. Integration results for the waxy products collected from the pyrolysis of PET powders with 0.0/1.0 (without catalyst), 2.0/1.0 ( $\left.\mathrm{W}_{\mathrm{ZSM}-5} / \mathrm{W}_{\mathrm{PET}}\right)$, 4.0/1.0 ( $\left.\mathrm{W}_{\mathrm{ZSM}-5} / \mathrm{W}_{\mathrm{PET}}\right)$, and $0.5 / 1.0\left(\mathrm{WNiCl}_{2} / \mathrm{W}_{\mathrm{PET}}\right)$ of $\mathrm{NiCl}_{2}$ at $600{ }^{\circ} \mathrm{C}$ for $30 \mathrm{~min}$, characterized by quantitative ${ }^{13} \mathrm{C}$ NMR with the assignment range shown in Table 2. The results are described as the percentage of carbon.

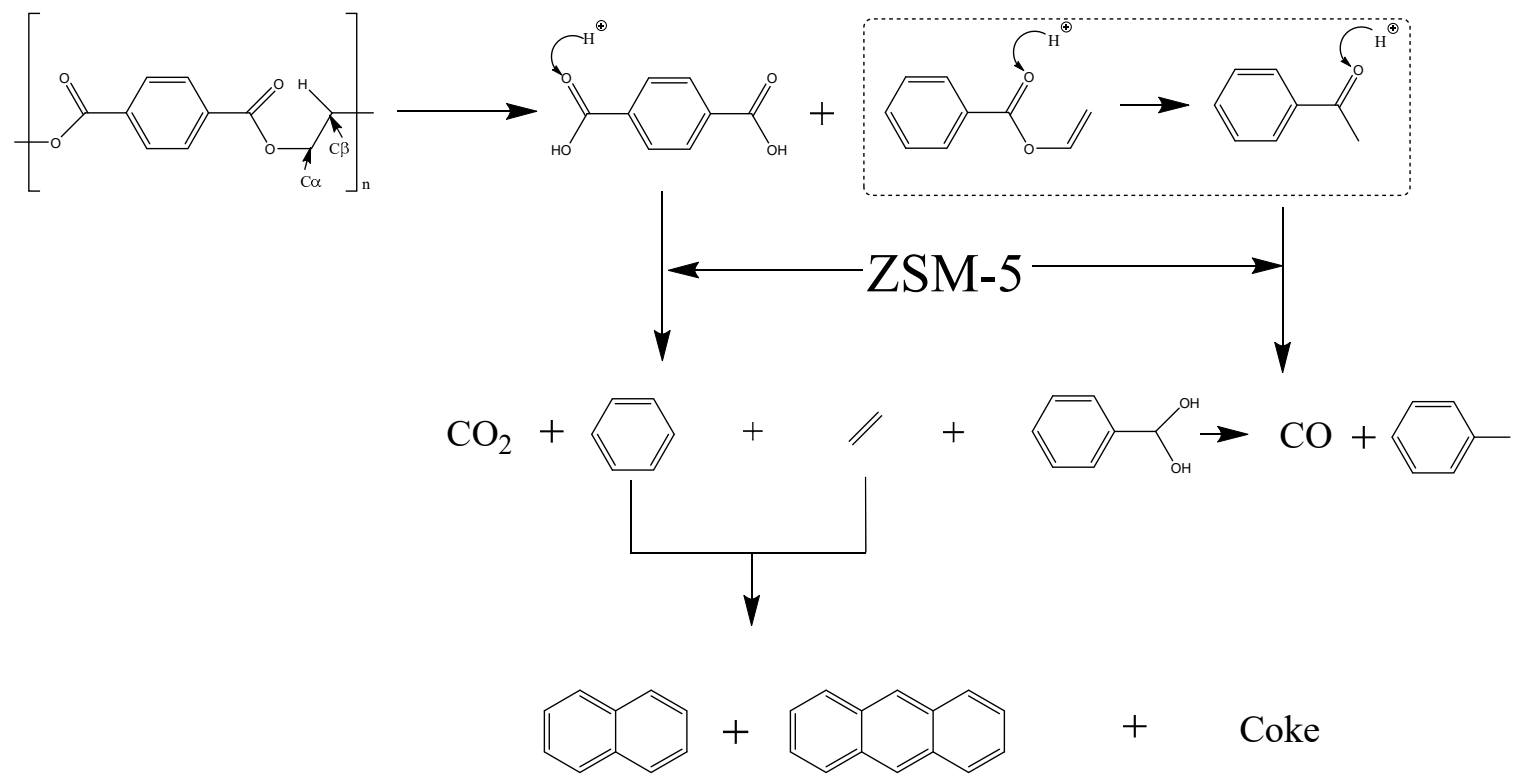

Figure 9. Possible decomposition pathways of PET pyrolysis.

\section{Conclusions}

The pyrolysis of PET with different dosages of ZSM- 5 zeolite and $\mathrm{NiCl}_{2}$ as a catalyst was carried out at different temperature $\left(450-600{ }^{\circ} \mathrm{C}\right)$ under $\mathrm{N}_{2}$ atmosphere. The yield of pyrolysis products produced from PET indicates that both the mass ratio of the catalyst to PET and temperature play a significant role in the distribution of products. The addition of $\mathrm{ZSM}-5$ and $\mathrm{NiCl}_{2}$ reduced the yield of the waxy product but increased the yield of gas. At low temperature $\left(450^{\circ} \mathrm{C}\right)$, the solid residue content was almost the same level after the use of ZSM-5 as the catalyst, while the yield of char sharply decreased by using $\mathrm{NiCl}_{2}$ as the catalyst. In contrast, it shows an analogous trend under high-temperature conditions $\left(600^{\circ} \mathrm{C}\right)$. The results suggest that ZSM-5 has little effect on the primary 
decomposition of PET, but it promotes the secondary volatile reactions. The use of $\mathrm{NiCl}_{2}$ as a catalyst will greatly improve the primary decomposition of PET to generate more liquid products. In addition, the detailed analysis of ${ }^{13} \mathrm{C}$ NMR spectrum for the waxy products indicates that the carbonyl groups and the aliphatic $\mathrm{C}-\mathrm{O}$ bonds are effectively removed by $42 \%$ and $20 \%$ respectively after the use of ZSM-5 as a catalyst compared to the pyrolysis of PET without a catalyst. In addition, the results of integration show that the waxy products have a relatively lower oxygen content in the presence of ZSM-5, which indicates that ZSM-5 could also promote the deoxygenation during the pyrolysis of PET.

Author Contributions: All of the authors contributed significantly to the completion of this article, but they had different roles in all aspects. Conceptualization, H.B. and H.J.; methodology, H.B.; software, Y.L.; validation, H.B. and H.J.; formal analysis, H.J.; investigation, R.W.; visualization, H.J.; supervision, H.J.; project administration, H.B.; funding acquisition, H.B. All authors have read and agreed to the published version of the manuscript.

Funding: This research was funded by the Postgraduate Research \& Practice Innovation Program of Jiangsu Province, grant number SJCX18_0023, National Science Foundation of China, grant number 51706044, the Natural Science Foundation of the Jiangsu of China, grant number BK20170666, and the Recruitment Program for Young Professionals in China. The APC was funded by Southeast University.

Conflicts of Interest: The authors declare no conflict of interest.

\section{References}

1. Plastic Europe, Plastic_The Facts 2017-2018. 2019. Available online: https://www.plasticseurope.org/en/ resources/publications (accessed on 1 October 2019).

2. Al-Salem, S.M.; Lettieri, P.; Baeyens, J. Recycling and recovery routes of plastic solid waste (PSW): A review. Waste Manag. 2009, 29, 2625-2643. [CrossRef] [PubMed]

3. Passamonti, F.J.; Sedran, U. Recycling of waste plastics into fuels. LDPE conversion in FCC. Appl. Catal. B Environ. 2012, 125, 499-506. [CrossRef]

4. Huber, G.W.; Iborra, S.; Corma, A. Synthesis of transportation fuels from biomass: Chemistry, catalysts, and engineering. Chem. Rev. 2006, 106, 4044-4098. [CrossRef] [PubMed]

5. Syamsiro, M.; Saptoadi, H.; Norsujianto, T.; Noviasri, P.; Cheng, S.; Alimuddin, Z.; Yoshikawa, K. Fuel Oil Production from Municipal Plastic Wastes in Sequential Pyrolysis and Catalytic Reforming Reactors. In Conference and Exhibition Indonesia Renewable Energy \& Energy Conservation (Indonesia Ebtke-Conex 2013); Adinurani, P.G., Nindita, A., Yudhanto, A.S., Sasmito, A., Eds.; Elsevier Science Bv: Amsterdam, The Netherlands, 2014; pp. 180-188.

6. Ippolito, N.M.; Cafiero, L.; Tuffi, R.; Ciprioti, S.V. Characterization of the residue of a commingled post-consumer plastic waste treatment plant: A thermal, spectroscopic and pyrolysis kinetic study. J. Therm. Anal. Calorim. 2019, 138, 3323-3333. [CrossRef]

7. Jin, Z.; Yin, L.; Chen, D.; Jia, Y.; Yuan, J.; Hu, Y. Co-pyrolysis characteristics of typical components of waste plastics in a falling film pyrolysis reactor. Chin. J. Chem. Eng. 2018, 26, 2176-2184. [CrossRef]

8. Artetxe, M.; Lopez, G.; Amutio, M.; Elordi, G.; Olazar, M.; Bilbao, J. Operating Conditions for the Pyrolysis of Poly-(ethylene terephthalate) in a Conical Spouted-Bed Reactor. Ind. Eng. Chem. Res. 2010, 49, $2064-2069$. [CrossRef]

9. Das, P.; Tiwari, P. Thermal degradation study of waste polyethylene terephthalate (PET) under inert and oxidative environments. Thermochim. Acta 2019, 679, 178340. [CrossRef]

10. Grause, G.; Handa, T.; Kameda, T.; Mizoguchi, T.; Yoshioka, T. Effect of temperature management on the hydrolytic degradation of PET in a calcium oxide filled tube reactor. Chem. Eng. J. 2011, 166, 523-528. [CrossRef]

11. Kumagai, S.; Hasegawa, I.; Grause, G.; Kameda, T.; Yoshioka, T. Thermal decomposition of individual and mixed plastics in the presence of $\mathrm{CaO}$ or $\mathrm{Ca}(\mathrm{OH})_{2}$. J. Anal. Appl. Pyrolysis 2015, 113, 584-590. [CrossRef]

12. Masuda, T.; Miwa, Y.; Hashimoto, K.; Ikeda, Y. Recovery of oil from waste poly (ethylene terephthalate) without producing any sublimate materials. Polym. Degrad. Stab. 1998, 61, 217-224. [CrossRef]

13. Du, S.; Valla, J.A.; Parnas, R.S.; Bollas, G.M. Conversion of Polyethylene Terephthalate Based Waste Carpet to Benzene-Rich Oils through Thermal, Catalytic, and Catalytic Steam Pyrolysis. ACS Sustain. Chem. Eng. 2016, 4, 2852-2860. [CrossRef] 
14. Xue, Y.; Johnston, P.; Bai, X. Effect of catalyst contact mode and gas atmosphere during catalytic pyrolysis of waste plastics. Energy Convers. Manag. 2017, 142, 441-451. [CrossRef]

15. Miandad, R.; Rehan, M.; Barakat, M.A.; Aburiazaiza, A.S.; Khan, H.; Ismail, I.M.I.; Dhavamani, J.; Gardy, J.; Hassanpour, A.; Nizami, A.-S. Catalytic Pyrolysis of Plastic Waste: Moving Toward Pyrolysis Based Biorefineries. Front. Energy Res. 2019, 7, 27. [CrossRef]

16. Al-asadi, M.; Miskolczi, N. Pyrolysis of polyethylene terephthalate containing real waste plastics using Ni loaded zeolite catalysts. In IOP Conference Series: Earth and Environmental Science; IOP Publishing: Bristol, UK, 2018; Volume 154.

17. Diaz-Silvarrey, L.S.; McMahon, A.; Phan, A.N. Benzoic acid recovery via waste poly (ethylene terephthalate) (PET) catalytic pyrolysis using sulphated zirconia catalyst. J. Anal. Appl. Pyrolysis 2018, 134, 621-631. [CrossRef]

18. Sogancioglu, M.; Ahmetli, G.; Yel, E. A Comparative Study on Waste Plastics Pyrolysis Liquid Products Quantity and Energy Recovery Potential. Energy Procedia 2017, 118, 221-226. [CrossRef]

19. Chattopadhyay, J.; Pathak, T.S.; Srivastava, R.; Singh, A.C. Catalytic co-pyrolysis of paper biomass and plastic mixtures (HDPE (high density polyethylene), PP (polypropylene) and PET (polyethylene terephthalate)) and product analysis. Energy 2016, 103, 513-521. [CrossRef]

20. Saha, G.R.; Das, T.; Handique, P.; Kalita, D.; Saikia, B.K. Copyrolysis of Low-Grade Indian Coal and Waste Plastics: Future Prospects of Waste Plastic as a Source of Fuel. Energy Fuels 2018, 32, 2421-2431. [CrossRef]

21. Sakata, Y.; Uddin, M.d.A.; Muto, A. Degradation of polyethylene and polypropylene into fuel oil by using solid acid and non-acid catalysts. J. Anal. Appl. Pyrolysis 1999, 51, 135-155. [CrossRef]

22. Özsin, G.; Pütün, A.E.; Pütün, E. Investigating the interactions between lignocellulosic biomass and synthetic polymers during co-pyrolysis by simultaneous thermal and spectroscopic methods. Biomass Convers. Biorefin. 2019, 9, 593-608. [CrossRef]

23. Sembiring, F.; Purnomo, C.W.; Purwono, S. Catalytic Pyrolysis of Waste Plastic Mixture. In IOP Conference Series: Earth and Environmental Science; IOP Publishing: Bristol, UK, 2018; Volume 316.

24. Geng, J.; Wang, W.-L.; Yu, Y.-X.; Chang, J.-M.; Cai, L.; Shi, S.Q. Adding nickel formate in alkali lignin to increase contents of alkylphenols and aromatics during fast pyrolysis. Bioresour. Technol. 2017, 227, 1-6. [CrossRef]

25. French, R.; Czernik, S. Catalytic pyrolysis of biomass for biofuels production. Fuel Process. Technol. 2010, 91, 25-32. [CrossRef]

26. Lei, X.; Bi, Y.; Zhou, W.; Chen, H.; Hu, J. Catalytic Fast Pyrolysis of Cellulose by Integrating Dispersed Nickel Catalyst with HZSM-5 Zeolite. In IOP Conference Series: Earth and Environmental Science; IOP Publishing: Bristol, UK, 2018; Volume 108.

27. Garcia-Perez, M.; Chaala, A.; Pakdel, H.; Kretschmer, D.; Roy, C. Characterization of Bio-Oils in Chemical Families. Biomass Bioenergy 2007, 31, 222-242. [CrossRef]

28. Dhahak, A.; Hild, G.; Rouaud, M.; Mauviel, G.; Burkle-Vitzthum, V. Slow pyrolysis of polyethylene terephthalate: Online monitoring of gas production and quantitative analysis of waxy products. J. Anal. Appl. Pyrolysis 2019, 142, 104664. [CrossRef]

29. Ben, H.; Ragauskas, A.J. NMR Characterization of Pyrolysis Oils from Kraft Lignin. Energy Fuels 2011, 25, 2322-2332. [CrossRef]

30. Kosa, M.; Ben, H.; Theliander, H.; Ragauskas, A.J. Pyrolysis oils from $\mathrm{CO}_{2}$ precipitated Kraft lignin. Green Chem. 2011, 13, 3196-3202. [CrossRef]

31. Venkatachalam, S.; Nayak, S.G.; Labde, J.V.; Gharal, P.R.; Rao, K.; Kelkar, A.K. Degradation and Recyclability of Poly (Ethylene Terephthalate). In Polyester; Saleh, H.E.-D., Ed.; INTECH Open Access Publisher: London, UK, 2012.

32. Çit, İ.; Sınağ, A.; Yumak, T.; Uçar, S.; Mısırlığlu, Z.; Canel, M. Comparative pyrolysis of polyolefins (PP and LDPE) and PET. Polym. Bull. 2010, 64, 817-834. [CrossRef]

33. Vouvoudi, E.C.; Achilias, D.S. Pyrolytic degradation of common polymers present in packaging materials. J. Therm. Anal. Calorim. 2019, 138, 2683-2689. [CrossRef]

34. Nait-Ali, L.K.; Colin, X.; Bergeret, A. Kinetic analysis and modelling of PET macromolecular changes during its mechanical recycling by extrusion. Polym. Degrad. Stab. 2011, 96, 236-246. [CrossRef]

35. Olcese, R.; Carre, V.; Aubriet, F.; Dufour, A. Selectivity of Bio-oils Catalytic Hydrotreatment Assessed by Petroleomic and GC*GC/MS-FID Analysis. Energy Fuels 2013, 27, 2135-2145. [CrossRef] 
36. Dzięcioł, M.; Trzeszczyński, J. Volatile products of poly (ethylene terephthalate) thermal degradation in nitrogen atmosphere. J. Appl. Polym. Sci. 2000, 77, 1894-1901. [CrossRef]

37. Thilakaratne, R.; Tessonnier, J.-P.; Brown, R.C. Conversion of methoxy and hydroxyl functionalities of phenolic monomers over zeolites. Green Chem. 2016, 18, 2231-2239. [CrossRef]

38. Yoshioka, T.; Grause, G.; Eger, C.; Kaminsky, W.; Okuwaki, A. Pyrolysis of poly (ethylene terephthalate) in a fluidised bed plant. Polym. Degrad. Stab. 2004, 86, 499-504. [CrossRef]

39. Shukla, S.R.; Kulkarni, K.S. Depolymerization of poly (ethylene terephthalate) waste. J. Appl. Polym. Sci. 2002, 85, 1765-1770. [CrossRef]

40. Catalytic Effects of Metal Chlorides on the Pyrolysis of Lignite|Energy \& Fuels. Available online: http: //pubs-acs-org-s.vpn.seu.edu.cn:8118/doi/10.1021/ef060477h (accessed on 4 March 2020).

(C) 2020 by the authors. Licensee MDPI, Basel, Switzerland. This article is an open access article distributed under the terms and conditions of the Creative Commons Attribution (CC BY) license (http://creativecommons.org/licenses/by/4.0/). 